\title{
Relationship between XRCC1 and XPD polymorphisms and the risk of the development of hepatocellular carcinoma: A case-control study
}

\author{
TAO YUAN ${ }^{1 *}$, SHAOLI DENG ${ }^{2 *}$, HONGMING LIU ${ }^{1}$, MENGGANG LIU ${ }^{1}$ and PING CHEN ${ }^{1}$ \\ Departments of ${ }^{1}$ Hepatobiliary Surgery and ${ }^{2}$ Clinical Laboratory Medicine, Institute of Surgery Research, \\ Daping Hospital, Third Military Medical University, Chongqing 400042, P.R. China
}

Received March 8, 2012; Accepted May 14, 2012

DOI: $10.3892 /$ etm.2012.581

\begin{abstract}
Hepatocellular carcinoma (HCC) is a serious public health issue, the incidence of which is considered to be closely related to tobacco smoking, alcohol consumption, hepatitis B virus (HBV) infection and family history. The DNA repair system is an important protective mechanism against the development of malignant cells induced by internal and external environmental factors. The aim of this study was to investigate the association of polymorphisms of XRCC1-194, XRCC1-280 and XPD-312 DNA repair genes and the risk of development of $\mathrm{HCC}$ in Han Chinese patients. A case-control design was used including 252 HCC inpatients and 250 healthy controls recruited and matched by age, gender, tobacco smoking, alcohol consumption, HBV infection and family history. XPD Asp312Asn, XRCC1 Arg194Trp and XRCC1 Arg280His genes were examined using a sequencing assay method. Distributions of the genotype frequency and odds ratio (OR) between the two groups were analyzed. The results demonstrated that there was no significant difference in the frequencies of XPD Asp312Asn, XRCC1 Arg194Trp and XRCC1 Arg280His in the HCC cases and the control group. In the stratified analysis of different allele genotypes, the frequency of the XRCC1-194 site genotype was not significantly different between the case and control group. The presence of the XRCC1 280His genotype was associated with a significantly increased risk of HCC under conditions of HBV infection and family history [OR (95\% CI): 1.68 (1.08-2.60), 4.20 (1.34-13.20), respectively]. Similarly, the XPD 312Asn significantly increased the risk of HCC under conditions of alcohol consumption, tobacco smoking, HBV infection and
\end{abstract}

Correspondence to: Professor Ping Chen, Department of Hepatobiliary Surgery, Daping Hospital, Third Military Medical University, Chongqing 400042, P.R. China

E-mail: dengs1072@yahoo.com.cn

*Contributed equally

Key words: hepatocellular carcinoma, genotype, polymorphisms, susceptibility family history [OR (95\% CI): 1.67 (1.10-2.60), 1.87 (1.18-2.96), 1.96 (1.24-3.10), 3.40 (1.32-8.76), respectively]. In conclusion, tobacco smoking and alcohol consumption are high risk factors of HCC for the XPD 312Asn genotype; HBV infection and family history increase the risk of HCC for the genotypes XRCC1 280His and XPD 312Asn.

\section{Introduction}

Hepatocellular carcinoma (HCC) is a common type of malignant tumor with a mortality rate of $20 / 100,000$. It is often aggressive with rapid development, which seriously threatens life and health. It has been found that human gene polymorphisms may be associated with genetic susceptibility for cancer. The interaction of environmental factors and genetic polymorphisms may play a crucial role in tumor development. Epidemiological studies suggest that chronic hepatitis B virus (HBV) infection, aflatoxin B1 (AFBl) intake in food, and longterm excessive alcohol consumption are major environmental risk factors for HCC. However, genetic susceptibility for HCC remains unclear. To date, the relationship between genetic polymorphisms and susceptibility to $\mathrm{HCC}$, and the relationship between HCC and the interaction of environmental factors and genetic polymorphisms are still poorly understood (1).

Epidemiological investigations have shown that the occurrence and development of tumors have a strong genetic predisposition. The genetic tendency may stem from the activation of oncogenes or silencing of tumor-suppressor genes, and also the absence or inhibition of DNA damage repair capacity. Therefore, DNA damage repair genes and susceptibility to cancers are cause for concern and subject to attention. HCC is the most common malignant tumor of the digestive system. As with other malignancies, the development of HCC is a multifactorial, multistep, multistage and multigene process (2-4). In recent years, DNA repair genes have been examined in cancer susceptibility studies (5). DNA damage and repair is a complex process involving a variety of enzymes and proteins. DNA repair capacity is crucial in maintaining genomic stability and normal function of cells. Mutations of relevant repair genes may lead to decreased DNA repair capacity of the whole genome. When the body is unable to efficiently repair DNA damage in a timely manner, 
genomic instability results which may lead to uncontrolled cell proliferation and tumorigenesis (6). The human X-ray repair cross complement 1 (XRCC1) and human excision repair gene xeroderma pigmentosum group D (XPD) broadly participate in DNA damage repair. In the current study, the objective was to analyze three SNP loci, XRCC1 Arg194Trp, XRCC1 Arg280His and XPD Asp312Asn, to investigate the relationship between polymorphisms and susceptibility to HCC.

\section{Materials and methods}

Study participants. From January 2009 to December 2010, 252 patients with HCC were recruited from the Third Affiliated Hospital of the Third Military Medical University in China. All patients were confirmed to have HCC by post-surgical pathology, and were not treated with pre-operative chemotherapy. In addition, 250 healthy control subjects were also recruited by matching the cases in terms of age and gender.

All the case and control subjects were genetically unrelated Han Chinese from Chongqing city and the surrounding metropolitan area in southwestern China. Informed consent was obtained from each subject prior to data collection, according to a protocol that was approved by the Medical Research Ethics Committee of Chongqing. Clinical pathological data and blood were collected from each participant.

The study was reviewed and approved by the Medical Research Ethics Committee of Chongqing. Informed consent was obtained from each subject prior to data collection.

Questionnaire survey. A face-to-face survey was conducted by trained investigators to collect data on variables such as age, gender, family history, tobacco smoking, alcohol consumption and HBV infection.

\section{Genotyping of the XRCC1 and XPD polymorphisms}

DNA extraction. Fasting venous blood $(2 \mathrm{ml})$ was obtained under vacuum in an anticoagulant-containing tube. After mixing, DNA was extracted using a genomic DNA extraction kit (Tiangen, China), and preserved at $-20^{\circ} \mathrm{C}$ for the PCR experiments.

Analysis of XPD and XRCC1 genetic polymorphisms. Sequencing was used to examine XPD Asp312Asn, XRCC1 Arg194Trp and XRCC1 Arg280His sites. For XRCC1 the forward primer of the Arg194Trp site was 5'-CTGACCTTG CGGGACCTTA-3', the reverse primer was 5'-GTCGCT GGCTGTGACTATG-3', and the product was 455 bp. For Arg280His, the forward primer was 5'-CAGTGGTGCTAA CCTAATC-3', and the reverse primer was 5'-AGTAGTCTG CTGGCTCTGG-3'. For XPD Asp312Asn, the forward primer was 5'-CTGTTGGTGGGTGCCCGTATCTGTTGGTCT-3', and the reverse primer was 5'-TAATATCGGGGCTCACCCT GCAGCACTTCCT-3'. The PCR reaction system consisted of $50 \mu \mathrm{l}$, containing 5 units TaqDNA polymerase, $0.2 \mathrm{mmol} / \mathrm{l}$ dNTP mix, $2 \mathrm{mmol} / 1 \mathrm{MgCl}_{2}$, $1 \mathrm{X}$ Taq buffer (all from Promega Co., Madison, WI, USA), and $0.4 \mu \mathrm{mol} / 1$ of the primers, respectively, with the template DNA $2 \mu \mathrm{l}$. The condition for PCR was $94^{\circ} \mathrm{C}$ for $5 \mathrm{~min}$, followed by $94^{\circ} \mathrm{C}$ for $45 \mathrm{sec}, 56^{\circ} \mathrm{C}$ for $45 \mathrm{sec}$ and $72^{\circ} \mathrm{C}$ for $45 \mathrm{sec}$, which lasted for 40 cycles, and a final extension at $72^{\circ} \mathrm{C}$ for $5 \mathrm{~min}$. All the primers were synthe- sized by Sangon Biological Engineering (Technology \& Services Co., Ltd., Shanghai, China).

Statistical analysis. SPSS for Windows 13.0 was used for the statistical analysis. The Chi-square test was used to compare the distribution of the genotype frequency between the two groups. The odds ratio (OR) and $95 \%$ confidence interval (CI) from non-conditional logistic regression was used to show the risk of HCC among the different genotypes. All statistical tests were two-sided and $\mathrm{P}<0.05$ was considered to indicate a statistically significant difference.

\section{Results}

Characteristics of the participants. A total of $252 \mathrm{HCC}$ patients and 250 healthy controls were recruited. Among the 252 HCC patients, 21 tumors were well-differentiated, 53 were moderately differentiated and 178 were poorly differentiated. The average age was $51.6 \pm 7.4$ years in the case group, and $52.1 \pm 6.7$ years in the control group. There was no difference between the two groups in terms of age, gender, tobacco smoking, alcohol consumption, family history and HBV infection status (all P>0.05) (Table I).

Comparison of genotype composition and allele frequency of XRCC1 and XPD genetic peptide locus. We determined the SNP distributions of these three genes by direct sequencing of the PCR products that were amplified from DNA samples taken from the cases and controls.

The three genotypes of the XRCC1-194 site were CC, CT and TT. The base distribution frequencies of $\mathrm{C}$ and $\mathrm{T}$ were 70.0 and $30.0 \%$ in the case group; 71.4 and $28.6 \%$ in the control group, respectively. The three genotypes of the XRCC1-280 site were GG, GA and AA. The base distribution frequencies of $\mathrm{G}$ and $\mathrm{A}$ were 87.1 and $12.9 \%$ in the case group; 90.2 and $9.8 \%$ in the control group, respectively. The three genotypes of the XPD-312 site were GG, GA and AA. The base distribution frequencies of $\mathrm{G}$ and $\mathrm{A}$ were 85.7 and $14.3 \%$ in the case group; 91.2 and $8.8 \%$ in the control group, respectively (Table II).

The Hardy-Weinberg genetic equilibrium test showed a good fit in the control group $(\mathrm{P}>0.05)$, which indicated that it was representative of the sample.

Distribution of XRCC1 and XPD gene SNPS. The link between the nine different genotypes of the two genes and the presence of HCC was analyzed. There was no difference in the distribution of the genotypes of the three sites XPD 312Asn, XRCC1 280His and XRCC1 194Trp between the HCC group and the control group.

Analysis of the three SNP site genotypes of the sXRCC1 and XPD genes, stratified by age, gender, tobacco smoking, alcohol consumption, surface antigen of HBV infection and family history, revealed that the three SNP sites had no interaction with age and gender, but had an interaction with alcohol consumption, tobacco smoking, family history of HCC and surface antigen of HBV infection. There was no difference in the frequency of the XRCC1 194 genotype between the case and control groups. Under conditions of alcohol consumption, the risk of HCC for the XRCC1 194Trp genotype was 1.29 times higher than that of the healthy controls. However, 
Table I. Characteristics of the hepatocellular carcinoma and control groups.

\begin{tabular}{|c|c|c|c|c|c|}
\hline \multirow[t]{2}{*}{ Characteristics } & \multicolumn{2}{|c|}{$\begin{array}{l}\text { Hepatocellular carcinoma group } \\
\qquad(\mathrm{n}=252)\end{array}$} & \multicolumn{2}{|c|}{$\begin{array}{l}\text { Control group } \\
\quad(n=250)\end{array}$} & \multirow[t]{2}{*}{ P-value } \\
\hline & $\mathrm{n}$ & $\%$ & $\mathrm{n}$ & $\%$ & \\
\hline \multicolumn{6}{|l|}{ Age (years) } \\
\hline$\geq 50$ & 149 & 59.1 & 143 & 57.2 & 0.72 \\
\hline$<50$ & 103 & 40.9 & 107 & 42.8 & \\
\hline Mean \pm SD & \multicolumn{2}{|c|}{$51.6 \pm 7.4$} & \multicolumn{2}{|c|}{$52.1 \pm 6.7$} & \\
\hline \multicolumn{6}{|l|}{ Gender } \\
\hline Male & 191 & 75.8 & 185 & 74.0 & 0.68 \\
\hline Female & 61 & 24.2 & 65 & 26.0 & \\
\hline \multicolumn{6}{|c|}{ Tobacco smoking } \\
\hline Yes & 168 & 66.7 & 169 & 67.6 & 0.85 \\
\hline No & 84 & 33.3 & 81 & 32.4 & \\
\hline \multicolumn{6}{|c|}{ Alcohol consumption } \\
\hline Yes & 197 & 75.4 & 190 & 76.0 & 0.60 \\
\hline No & 55 & 24.6 & 60 & 24.0 & \\
\hline \multicolumn{6}{|c|}{ HBV antigen (+) } \\
\hline Yes & 203 & 80.6 & 194 & 77.6 & 0.44 \\
\hline No & 49 & 19.4 & 56 & 22.4 & \\
\hline \multicolumn{6}{|l|}{ Family history } \\
\hline Yes & 37 & 14.7 & 35 & 14.0 & 0.90 \\
\hline No & 215 & 85.3 & 215 & 86.0 & \\
\hline
\end{tabular}

Table II. Genotypes of the XRCC1 and XPD genes in the hepatocellular carcinoma and control groups.

\begin{tabular}{|c|c|c|c|c|}
\hline Genotype & Hepatocellular carcinoma group & Control group & OR $(95 \% \mathrm{CI})$ & P-values \\
\hline \multicolumn{5}{|l|}{ XPD 312} \\
\hline GG & 192 & 207 & 1.00 & 0.08 \\
\hline $\mathrm{GA}+\mathrm{AA}$ & 60 & 43 & $1.56(1.02-2.22)$ & \\
\hline AA & 2 & 1 & & \\
\hline G (Asp) frequency & $85.7 \%$ & $91.2 \%$ & & \\
\hline A (Asn) frequency & $14.3 \%$ & $8.8 \%$ & & \\
\hline \multicolumn{5}{|l|}{ XRCC1 280} \\
\hline GG & 193 & 206 & 1.00 & 0.12 \\
\hline $\mathrm{GA}+\mathrm{AA}$ & 59 & 44 & $1.43(0.97-2.10)$ & \\
\hline AA & 6 & 5 & & \\
\hline $\mathrm{G}$ (Arg) frequency & $87.1 \%$ & $90.2 \%$ & & \\
\hline A (His) frequency & $12.9 \%$ & $9.8 \%$ & & \\
\hline \multicolumn{5}{|l|}{ XRCC1 194} \\
\hline $\mathrm{CC}$ & 119 & 128 & 1.00 & 0.42 \\
\hline $\mathrm{CT}+\mathrm{TT}$ & 133 & 122 & $1.17(0.87-1.59)$ & \\
\hline TT & 18 & 21 & & \\
\hline $\mathrm{C}(\mathrm{Arg})$ frequency & $70.0 \%$ & $71.4 \%$ & & \\
\hline $\mathrm{T}(\mathrm{Trp})$ frequency & $30.0 \%$ & $28.6 \%$ & & \\
\hline
\end{tabular}

no statistical significance was found $(\mathrm{P}>0.05)$. For factors of exposure to HBV infection and family history, there was a significant difference in the frequency of XRCC1 $280 \mathrm{His}$ between the HCC and healthy control; the OR values and $95 \%$
CIs were 1.68 (1.08-2.60) and 4.20 (1.34-13.20). With exposure to alcohol consumption, the risk of HCC for XRCC1 280His genotype was 1.51 times higher than that of the healthy control. However, no statistical significance was found $(\mathrm{P}>0.05)$. Under 
Table III. Analysis of the distribution of XRCC1 and XPD triple-location genotypes in hepatocellular carcinoma (HCC) and control groups stratified according to alcohol consumption.

\begin{tabular}{|c|c|c|c|c|c|c|c|c|}
\hline \multirow[t]{2}{*}{ Genotype } & \multicolumn{4}{|c|}{ Alcohol consumption (+) } & \multicolumn{4}{|c|}{ Alcohol consumption (-) } \\
\hline & $\begin{array}{l}\text { HCC group } \\
\text { (n) }\end{array}$ & $\begin{array}{l}\text { Control } \\
\text { group (n) }\end{array}$ & OR $(95 \%$ CI $)$ & P-values & $\begin{array}{l}\text { HCC group } \\
\text { (n) }\end{array}$ & $\begin{array}{l}\text { Control } \\
\text { group (n) }\end{array}$ & OR $(95 \%$ CI $)$ & P-values \\
\hline \multicolumn{9}{|c|}{ XRCC1 Arg194Trp } \\
\hline $\mathrm{CC}$ & 85 & 94 & 1.00 & 0.22 & 34 & 34 & 1.00 & 0.70 \\
\hline $\mathrm{CT}+\mathrm{TT}$ & 112 & 96 & $1.29(0.91-1.82)$ & & 21 & 26 & $0.81(0.58-1.64)$ & \\
\hline \multicolumn{9}{|c|}{ XRCC1 Arg280His } \\
\hline GG & 143 & 152 & 1.00 & 0.10 & 50 & 54 & 1.00 & 1.00 \\
\hline $\mathrm{GA}+\mathrm{AA}$ & 54 & 38 & $1.51(0.99-2.30)$ & & 5 & 6 & $0.79(0.28-2.18)$ & \\
\hline \multicolumn{9}{|c|}{ XPD Asp312Asn } \\
\hline GG & 144 & 156 & 1.00 & 0.04 & 48 & 51 & 1.00 & 0.79 \\
\hline $\mathrm{GA}+\mathrm{AA}$ & 53 & 34 & $1.67(1.10-2.60)$ & & 7 & 9 & $0.86(0.35-2.12)$ & \\
\hline
\end{tabular}

OR values were adjusted by gender, age, tobacco smoking, HBV antigen and family history.

Table IV. Analysis of the distribution of the XRCC1 and XPD triple-location genotypes in hepatocellular carcinoma (HCC) group and control group stratified according to tobacco smoking status.

\begin{tabular}{|c|c|c|c|c|c|c|c|c|}
\hline \multirow[t]{2}{*}{ Genotype } & \multicolumn{4}{|c|}{ Tobacco smoking $(+)$} & \multicolumn{4}{|c|}{ Tobacco smoking (-) } \\
\hline & 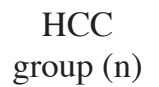 & $\begin{array}{l}\text { Control } \\
\text { group (n) }\end{array}$ & OR $(95 \% \mathrm{CI})$ & P-values & $\begin{array}{c}\text { HCC } \\
\text { group (n) }\end{array}$ & $\begin{array}{l}\text { Control } \\
\text { group (n) }\end{array}$ & OR $(95 \% \mathrm{CI})$ & P-values \\
\hline \multicolumn{9}{|c|}{ XRCC1 Arg194Trp } \\
\hline $\mathrm{CC}$ & 78 & 81 & 1.00 & 0.83 & 41 & 47 & 1.00 & 0.28 \\
\hline $\mathrm{CT}+\mathrm{TT}$ & 90 & 88 & $1.05(0.73-1.52)$ & & 43 & 34 & $1.48(0.87-2.52)$ & \\
\hline \multicolumn{9}{|c|}{ XRCC1 Arg280His } \\
\hline GG & 125 & 136 & 1.00 & 0.19 & 68 & 70 & 1.00 & 0.40 \\
\hline $\mathrm{GA}+\mathrm{AA}$ & 43 & 33 & $1.38(0.88-2.18)$ & & 16 & 11 & $1.48(0.72-3.04)$ & \\
\hline \multicolumn{9}{|c|}{ XPD Asp312Asn } \\
\hline GG & 120 & 139 & 1.00 & 0.02 & 72 & 68 & 1.00 & 0.83 \\
\hline $\mathrm{GA}+\mathrm{AA}$ & 48 & 30 & $1.87(1.18-2.96)$ & & 12 & 13 & $0.89(0.42-1.84)$ & \\
\hline
\end{tabular}

OR values were adjusted by gender, age, alcohol consumption, HBV antigen and family history.

conditions of alcohol consumption, tobacco smoking, HBV infection and family history, there was a significant difference in the frequency of the XPD 312Asn genotype between the HCC and healthy controls; the OR values and 95\% CIs were 1.67 (1.10-2.60), 1.87 (1.18-2.96), 1.96 (1.24-3.10), 3.40 (1.32-8.76) (Tables III-VI).

\section{Discussion}

The causes of HCC may relate to population or individual susceptibility to disease, and tumor-related genes including DNA repair genes and metabolic enzyme genes. The SNPs of these genes may result in different susceptibilities to the same carcinogens (7). Defective or lowered repair capacity of DNA caused by the polymorphisms of DNA repair genes increases the risk of mutations and carcinogenesis (8). The X-ray repair cross-complementing gene 1 (XRCC1) was the first mammalian gene found to affect the sensitivity of cells to ionizing radiation. It is widely involved in the repair of DNA damage. The XRCC1, $33 \mathrm{~kb}$ in size, is located on human chromosome 19q13.2-19q13.3, and contains 17 exons encoding 633 amino acid residues (9). Sequence analysis revealed that the XRCC1 gene has several polymorphism sites, among which C26304T and G27466A are the two most common SNP sites that lead to changes in the corresponding amino acid residues Arg194Trp and Arg280His, respectively (10). Studies demonstrated that polymorphisms of XRCC1 194 and XRCC1 280 were associated with susceptibility to esophageal cancer, gastric cancer, lung cancer, breast cancer and other types of cancers (11-14). However, little is known regarding the association between polymorphisms of these two genes and susceptibility to HCC. $\mathrm{XPD} / \mathrm{ERCC} 2$ is an ATP-dependent DNA helicase (8), which is 
Table V. Analysis of the distribution of the XRCC1 and XPD triple-location genotypes in hepatocellular carcinoma and control groups stratified according to HBV antigen.

\begin{tabular}{|c|c|c|c|c|c|c|c|c|}
\hline \multirow[t]{2}{*}{ Genotype } & \multicolumn{4}{|c|}{ HBsAg (+) } & \multicolumn{4}{|c|}{ HBsAg (-) } \\
\hline & $\begin{array}{l}\text { HCC group } \\
\text { (n) }\end{array}$ & $\begin{array}{l}\text { Control } \\
\text { group }(n)\end{array}$ & $\begin{array}{c}\text { OR } \\
(95 \% \mathrm{CI})\end{array}$ & P-values & $\begin{array}{l}\text { HCC group } \\
\text { (n) }\end{array}$ & $\begin{array}{l}\text { Control } \\
\text { group (n) }\end{array}$ & $\begin{array}{c}\text { OR } \\
(95 \% \mathrm{CI})\end{array}$ & P-values \\
\hline \multicolumn{9}{|c|}{ XRCC1 Arg194Trp } \\
\hline $\mathrm{CC}$ & 93 & 100 & 1.00 & 0.27 & 26 & 28 & 1.00 & 0.85 \\
\hline $\mathrm{CT}+\mathrm{TT}$ & 110 & 94 & $1.26(0.89-1.76)$ & & 23 & 28 & $0.89(0.46-1.71)$ & \\
\hline \multicolumn{9}{|c|}{ XRCC1 Arg280His } \\
\hline GG & 153 & 163 & 1.00 & 0.04 & 40 & 43 & 1.00 & 0.63 \\
\hline $\mathrm{GA}+\mathrm{AA}$ & 50 & 31 & $1.68(1.08-2.60)$ & & 9 & 13 & $0.74(0.33-1.66)$ & \\
\hline \multicolumn{9}{|c|}{ XPD Asp312Asn } \\
\hline GG & 153 & 166 & 1.00 & 0.01 & 39 & 41 & 1.00 & 0.76 \\
\hline $\mathrm{GA}+\mathrm{AA}$ & 50 & 28 & $1.96(1.24-3.10)$ & & 10 & 15 & $1.13(0.96-1.79)$ & \\
\hline
\end{tabular}

OR values were adjusted by gender, age, tobacco smoking, alcohol consumption and family history.

Table VI. Analysis of the distribution of XRCC1 and XPD triple-location genotypes in hepatocellular carcinoma and control groups stratified according to family history of HCC.

\begin{tabular}{|c|c|c|c|c|c|c|c|c|}
\hline \multirow[t]{2}{*}{ Genotype } & \multicolumn{4}{|c|}{ Family history (+) } & \multicolumn{4}{|c|}{ Family history (-) } \\
\hline & $\begin{array}{l}\text { HCC group } \\
\text { (n) }\end{array}$ & $\begin{array}{l}\text { Control } \\
\text { group (n) }\end{array}$ & OR $(95 \% \mathrm{CI})$ & P-values & $\begin{array}{l}\text { HCC group } \\
\text { (n) }\end{array}$ & $\begin{array}{l}\text { Control } \\
\text { group (n) }\end{array}$ & OR $(95 \% \mathrm{CI})$ & P-values \\
\hline \multicolumn{9}{|c|}{ XRCC1 Arg194Trp } \\
\hline $\mathrm{CC}$ & 12 & 18 & 1.00 & 0.15 & 107 & 110 & 1.00 & 0.85 \\
\hline $\mathrm{CT}+\mathrm{TT}$ & 25 & 17 & $2.21(0.97-5.02)$ & & 108 & 105 & $1.06(0.76-1.47)$ & \\
\hline \multicolumn{9}{|c|}{ XRCC1 Arg280His } \\
\hline GG & 24 & 31 & 1.00 & 0.03 & 169 & 175 & 1.00 & 0.55 \\
\hline $\mathrm{GA}+\mathrm{AA}$ & 13 & 4 & $4.20(1.34-13.20)$ & & 46 & 40 & $1.16(0.78-1.76)$ & \\
\hline \multicolumn{9}{|c|}{ XPD Asp312Asn } \\
\hline GG & 20 & 28 & 1.00 & 0.03 & 172 & 179 & 1.00 & 0.46 \\
\hline $\mathrm{GA}+\mathrm{AA}$ & 17 & 7 & $3.40(1.32-8.76)$ & & 43 & 36 & $1.26(0.82-1.93)$ & \\
\hline
\end{tabular}

OR values were adjusted by gender, age, tobacco smoking, alcohol consumption and HBV antigen.

an important part of the type II transcription factor $\mathrm{H}$ (TF II H) complex, involved in nucleotide excision repair (NER). Numerous single nucleotide polymorphisms have been found in the XPD gene (10), of which the XPD 751 site is most studied. Heterozygous XPD 751 and mutant homozygous (Lys/Gln and Gln/Gln) genotypes have been shown to result in significantly lower NER capacity $(15)$. Long et al $(23,24)$ reported on XRCC1 and XPD polymorphisms and susceptibility to hepatocellular carcinoma. However, a combined analysis of the relationship between XPD and XRCC1 gene polymorphisms and susceptibility to HCC has not been reported. Through a case-control study design, we investigated the polymorphism distribution of the three sites on XRCC1 194, XRCC1 280 and XPD 312 genes, and analyzed the relationship between polymorphisms of the three sites and susceptibility to HCC, which provided evidence for the prevention and treatment of HCC.
The frequencies of XRCC1 and XPD 312 alleles all have ethnic and geographical differences. Shen et al (10) reported that the frequencies of XRCC1 194Trp and 280His alleles in healthy individuals in San Francisco, CA, USA were 25 and $8 \%$, respectively. The statistics on Caucasians in Europe and North America revealed the frequencies of the Asn allele on the XPD312 site to be 33 to $38 \%$, respectively. However, it was found to be lower, $6 \%$, in the Chinese population (16). Meanwhile, other authors (17-19) reported frequencies of 5, 6, 5 and $27 \%$ in Egyptian, Caucasian, African-American and Chinese Taiwan populations, respectively. The study demonstrated that the allelic frequencies of XRCC1 194T, XRCC1 280A and XPD 312A in healthy controls were $28.6,9.8$ and $8.8 \%$, respectively, which were similar to a report in a Chinese population in Taiwan, but was quite different from that in Europe and America, possibly due to ethnic and geographical differences. 
Cancer susceptibility has been associated with multiple genes. As with other malignant tumors, the development of HCC is due to the joint effect of genetic and environmental factors. In the present study, XRCC1 194T, XRCC1 280A, XPD 312A gene polymorphisms were stratified according to four factors, including tobacco smoking, alcohol consumption, HBV infection, and family history of HCC. The results revealed that among the four risk factors, the XRCC1 194Trp genotype did not increase the risk of HCC. Although the risk of HCC for the XRCC1 194Trp genotype was 1.29 times higher than that of the XRCC1 194Arg genotype with exposure to alcohol, there was no significant difference between them $(\mathrm{P}>0.05)$. However, Kiran et al (20) reported that XRCC1 194Trp increased the risk of susceptibility to HCC in hepatitis patients in Indians (OR=2.27; 95\% CI, 1.01-5.08; $\mathrm{P}<0.001)$. Furthermore, when XRCC1 194Trp was combined with XRCC1 280His or with XRCC1 399Gln, the risk of hepatitisrelated HCC was markedly increased, which indicated that the $\mathrm{XRCC} 1$ gene polymorphism may have a certain role in the risk of hepatitis virus-related HCC in Indians. The differences in results may be related to ethnic and regional differences. The polymorphism of XRCC1 Arg280His and XPD Asp312Asn was analyzed according to four risk factors, and demonstrated that the XRCC1-280 polymorphism had no effect on tobacco smoking- and alcohol consumption-related HCC, while it conferred a high risk on HBV infection- and family historyrelated HCC. Furthermore, the XPD312 wild-type genotype had a strong role in promoting HCC under conditions of tobacco smoking, alcohol consumption, HBV infection and family history.

The present study had a number of limitations. First, all patients with HCC were recruited from hospital patients, and the sample size was limited. Second, healthy controls were recruited after matching the HCC patients in regards to age, gender, family history, tobacco smoking, alcohol consumption, and HBV infection, which may have potential selection bias and influence on the results and conclusions. Finally, various studies have been previously carried out concerning the relationship between gene polymorphisms and tumors producing various results $(21,22)$.

In summary, XPD 312Asn genotypes significantly increased the risk of $\mathrm{HCC}$ in a population with alcohol consumption, tobacco smoking, HBV infection, and family history of HCC. XRCC1 280His genotypes significantly increased the risk of HCC in a population with HBV infection and family history of HCC. Further research is required to confirm these preliminary results. An increased sample size, improvement in experimental design and methods, and additional indicators of therapeutic efficacy and prognosis would be of value. Systematic follow-up and observation of populations with exposure factors may be carried out in order to prevent $\mathrm{HCC}$, and provide a possibility for early detection and treatment.

\section{Acknowledgements}

This work was supported in part by a grant from the National Natural Science Foundation of China (no. 81101199 and 30972895) and from the Natural Science Foundation Project of the Third Military Medical University (no. 2008-1087).

\section{References}

1. Silvestri L, Sonzogni L, De Silvestri A, et al: CYP enzyme polymorphisms and susceptibility to HCV-related chronic liver disease and liver cancer. Int J Cancer 104: 310-317, 2003.

2. Kirk GD, Lesi OA, Mendy M, et al: 249(ser) TP53 mutation in plasma DNA, hepatitis B viral infection, and risk of hepatocellular carcinoma. Oncogene 24: 5858-5867, 2005.

3. Hara A, Sakata K, Yamada Y, et al: Suppression of $\beta$-catenin mutation by dietary exposure of auraptene, a citrus antioxidant, in N,N-diethylnitrosamine-induced hepatocellular carcinomas in rats. Oncol Rep 14: 345-351, 2005.

4. Marrero JA, Fontana RJ, Fu S, et al: Alcohol, tobacco and obesity are synergistic risk factors for hepatocellular carcinoma. J Hepatol 42: 218-224, 2005.

5. Zhang X, Miao X, Liang G, et al: Polymorphisms in DNA base excision repair genes ADPRT and XRCC1 and risk of lung cancer. Cancer Res 65: 722-726, 2005.

6. Gerlitz G: HMGNs. DNA repair and cancer. Biochim Biophys Acta 1799: 80-85, 2010.

7. Song DK, Xing DL, Zhang LR, et al: Association of NAT2, GSTM1, GSTT1, CYP2A6, and CYP2A13 gene polymorphisms with susceptibility and clinicopathologic characteristics of bladder cancer in Central China. Cancer Detect Prev 32: 416-423, 2009.

8. Ginsberg G, Angle K, Guyton K and Sonawane B: Polymorphism in the DNA repair enzyme XRCC1: Utility of current database and implications for human health risk assessment. Mutat Res 727: 13-15, 2011.

9. Lindahl T and Wood RD: Quality control by DNA repair. Science 286: 1897-1905, 1999.

10. Shen MR, Jones LM and Mohrenweiser H: Nonconservative amino acid substitution variants exist at polymorphic frequency in DNA repair genes in healthy humans. Cancer Res 58: 604-608, 1998.

11. Xing D, Qi J, Miao X, et al: Polymorphisms of DNA repair genes XRCC1 and XPD and their associations with risk of esophageal squamous cell carcinoma in a Chinese population. Int $\mathrm{J}$ Cancer 100: 600-605, 2002.

12. Lee SG, Kim B, Choi J, et al: Genetic polymorphisms of XRCC1 and risk of gastric cancer. Cancer Lett 187: 53-60, 2002.

13. Park JY, Lee SY, Jeon HS, et al: Polymorphism of the DNA repair gene XRCC1 and risk of primary lung cancer. Cancer Epidemiol Biomarkers Prev 11: 23-27, 2002.

14. Kim SU, Park SK, Yoo KY, et al: XRCC1 genetic polymorphism and breast cancer risk. Pharmacogenetics 12: 335-338, 2002.

15. Au WW, Salama SA and Sierra-Torres CH: Functional characterization of polymorphisms in DNA repair genes using cytogenetic challenge assays. Environ Health Perspect 111: 1843-1850, 2003.

16. Liang G, Xing D, Miao XD, et al: Sequence variations in the DNA repair gene XPD and risk of lung cancer in a Chinese population. Int J Cancer 105: 669-673, 2003.

17. Abdel-Rahman SZ, Soliman AS, Bondy ML, et al: Inheritance of the 194Trp and the 399Gln variant alleles of the DNA repair gene XRCC1 are associated with increased risk of early-onset colorectal carcinoma in Egypt. Cancer Lett 159: 79-86, 2000.

18. David-Beabes GL and London SJ: Genetic polymorphism of $\mathrm{XRCC} 1$ and lung cancer risk among African-Americans and Caucasians. Lung Cancer 34: 333-339, 2001.

19. Lunn RM, Langlois RG, Hsieh LL, et al: XRCC1 polymorphisms: effects on aflatoxin B1-DNA adducts and glycophorin A variant frequency. Cancer Res 59: 2557-2561, 1999.

20. Kiran M, Saxena R, Chawla YK, et al: Polymorphism of DNA repair gene XRCC1 and hepatitis-related hepatocellular carcinoma risk in Indian population. Mol Cell Biochem 327: 7-13, 2009.

21. Cheng L, Spitz MR, Hong WK, Wei Q: Reduced expression levels of nucleotide excision repair genes in lung cancer. Carcinogenesis 21: 1527-1530, 2000.

22. Vogel U, Nexø BA, Tjønneland A, et al: ERCC1, XPD and RAI mRNA levels in lymphocytes are not associated with lung cancer risk in a prospective study of Danes. Mutat Res 593: 88-96, 2006.

23. Long XD, Ma Y, Zhou YF, et al: XPD codon 312 and 751 polymorphisms, and AFB1 exposure, and hepatocellular carcinoma risk. BMC Cancer 17: 400, 2009.

24. Long XD, Ma Y, Wei YP, et al: The polymorphisms of GSTM1, GSTT1, HYL1*2, and XRCC1, and aflatoxin B1-related hepatocellular carcinoma in Guangxi population, China. Hepatol Res 36: 48-55, 2006. 